\title{
HACIA UN MERCADO COMÚN DE LOS CUERPOS. LA UTILIZACIÓN DE LOS ARQUETIPOS FEMENINOS COMO INSTRUMENTO PARA LA PROMOCIÓN POLITICA EN LOS AÑOS SESENTA
}

\author{
CARMEN ROMO PARRA
}

Universidad de Málaga

\section{EL PAPEL DE LAS MUJERES EN EL DESARROLLO}

El contexto bifocal desde el que se plantean los caminos del desarrollo económico desvirtúa el protagonismo innegable que en los mismos desempeñan las mujeres, dentro de un horizonte en el cual la planificación del crecimiento esconde tanto el indiscutible papel activo de las mujeres en la consolidación de éste, como su discriminación en la distribución de los beneficios devengados. En este sentido muchas autoras, entre ellas E. Boserup, han señalado que el desarrollo económico "puede implicar una dinámica de atraso y represión para otros aspectos sociales, como las relaciones de género» ${ }^{1}$.

Sin embargo, pese a esta ceguera intencionada que aún hoy padecemos, la utilización de un estereotipo femenino moderno, de independencia e igualitario, se viene esgrimiendo como indicador de los niveles de progreso, atendiendo a juicios de valor que constituyen un denominador común a todo tipo de economías, hasta proyectar en el presente, con mayor o menor intensidad, fórmulas disfuncionales, relativas e incluso contradictorias ${ }^{2}$.

Es más que explícita, pues, la estrecha relación entre las opciones en política económica y la demagogia de los discursos alrededor de la mujer que vienen a apoyarla. Así, la construcción de la feminidad ha servido para exponer y refrendar de cara a la comunidad internacional -especialmente en los países

1. HbsSFelD, Karen: «El género y la economía política: una reformulación de las teorías del desarrollo", en Nuevas perspectivas sobre la Mujer. Tomo II, Madrid, Universidad Autónoma de Madrid, 1982, p. 234

2. Sobre la situación subordinada de las mujeres en el desarrollo, ver Domínguez Martín, Rafael: "Teorías de la división del trabajo y enfoque del género", Arenal. Revista de Historia de las Mujeres,

7-1 (2000), especialmente las pp. 192-202. 
en vías de desarrollo- el buen funcionamiento de los canales de producción y de distribución del bienestar. Desde estas coordenadas, la representación del mundo de las mujeres se ha utilizado extensiva e intensivamente en un amplio espectro que proyecta líneas de fuga hacia distintos puntos, partiendo, en definitiva, desde el marketing empresarial hacia el consenso de políticas económicas y sociales.

Sobre estas bases, el catálogo de arquetipos femeninos se instrumentalizará como factor de reclamo publicitario en uno de los sectores de mayor auge en la década de los sesenta: el turismo. Como empresa que juega con la construcción de los deseos y la realización de expectativas, y, cómo no, donde la oferta y la demanda crean el espacio de intersección de los beneficios, su universo se rellena de iconos y lugares comunes tan atractivos como, en muchos casos, inconsistentes. Todo ello en un tejido donde la relación entre símbolos y objetos se deriva del hecho de que el símbolo -palabra o imagen- contribuye a dar al objeto su identidad, su claridad, su definición, transformando "una realidad concreta en realidad experimentada y sentida" como parte indispensable de toda experiencia ${ }^{3}$, toda vez que las imágenes son importantes fuentes de conocimiento de nuestra sociedad y, por tanto, de nuestro papel personal en ella.

Sin embargo, desde nuestra perspectiva, la utilización de la imagen femenina como elemento de interés en los diseños de recepción turística no ha contado hasta el momento con una atención especial por parte de la investigación al respecto, en favor del análisis de la relación establecida entre el cambio en la condición social de la mujer y el fenómeno turístico, volcado principalmente en dos vías paralelas. Se viene indagando, en primer término, sobre el efecto liberador que proporciona la actividad laboral en el sector por cuanto, en líneas generales, demanda sobre todo a mujeres y a jóvenes, abriendo un coto de mayor posibilidad de independencia económica que les permite, a la vez, salir del cerrado círculo doméstico. Con todo, los enfoques de género permiten evidenciar los numerosos sesgos de esta premisa: discriminación salarial, doble jornada, "doble presencia», "techo de cristal», ausencia de tiempo libre para las mujeres ${ }^{4}$. De otro lado, se insiste en el estudio de la influencia del turismo sobre los cambios en la moral sexual y en los patrones de comportamiento de los núcleos receptores -hacia la consolidación de un «mercado común de los cuerpos», como apuntaba Maurois-, tema que ha generado un amplio debate en el marco de la sociología de la vida cotidiana, al que se ha sumado la histo-

3. Graburn, Nelson H.: «Turismo: el viaje sagrado", en Valene L. Smith (coord.): Anfitriones e invitados, Madrid, Endymión, 1992, p.63.

4. Ruíz Franco, $M^{a}$ Rosario: «Nuevos horizontes para las mujeres de los años sesenta: la ley de 22 de julio de 1961", Arenal. Revista de Historia de las Mujeres, 2-2 (1995), pp. 247-268. Díaz Sánchez, Pilar: El trabajo de las mujeres en el textil madrileño. Racionalización industrial y experiencias de género (1959-1986), Málaga, Atenea-Universidad, 2001. Romo PARRA, Carmen: «Tiempo de trabajos. Los límites difusos de las horas excedentes para las mujeres en España (1964-1975)", Arenal. Revista de Historia de las Mujeres, 8-1 (2001), pp. 55-81. 
ria de las mujeres ${ }^{5}$. En su epicentro, Wilson, argumentando que estas actitudes son parte del sistema de relaciones varón-mujer enraizadas en tradiciones históricas, concluye que "el turismo meramente confirma patrones y valores existentes en la cultura». Bouhdiba, por su parte, advierte contra la "tendencia a atribuir directamente al turismo todos los cambios indeseables», dado que, desde su punto de vista, éste únicamente acelera las rupturas que son producto de otras fuerzas ${ }^{6}$.

En el marco de los parámetros en los que centramos nuestro interés, el franquismo comercializó un perfil de las españolas que, en una doble vertiente, las situaba como máximas fedatarias del tipismo de un pasado romantizado, por sus oficios y maneras de ser y, de otro, dibujaba el paradigma vivo del progreso social devengado por el régimen, a través del fenotipo de las chicas de las últimas generaciones ${ }^{7}$. Frente a todas ellas, las extranjeras que visitan nuestras costas constituyen el emblema de los hallazgos de la opulencia occidental, como un reflejo de futuro que, sin embargo, debía ser depurado. Las primeras, madres e hijas, dan forma al paraíso ufano de tranquilidad y reposo que España ofertaba como destino turístico, con todas las ventajas del mundo moderno. Las segundas ofrecen la apertura a mundos posibles a partir de la creación de un espacio lúdico, de erotismo velado y posibilidades sexuales. Si las extranjeras son objeto de atractivo eminentemente para los viajeros nacionales, insignias del confort importado, las españolas simbolizan el espíritu y la esencia del mundo previo al pecado original, de lo distinto, de lo otro, según apuntan Rosario Ruiz Franco, Pilar Amador, $M^{a}$ Teresa Gallego y Carmen Molinero, entre otras autoras $^{8}$. Todo ello dentro de un ámbito publicitario en el cual «los anuncios

5. Ver esta noción en AbeLLA, Rafael: La vida cotidiana en España bajo el régimen de Franco, Barcelona, Argos-Vergara, 1985, p.179. Sobre la creación de nuevas pautas de conducta y valores y su repercusión en la vida de las mujeres, Romo PARRA, Carmen: «¿Del encuadre a la integración de la mujer?: la institucionalización del "ocio activo» durante el Primer Plan de Desarrollo», en $\mathrm{M}^{\mathrm{a}}$ Dolores Ramos y $\mathrm{M}^{\mathrm{a}}$ Teresa Vera (eds.): El trabajo de las mujeres. Pasado y presente, Tomo III, Málaga, Diputación Provincial de Málaga, 1996, pp. 149-158 y Romo PARRA, Carmen y VerA, Ma Teresa: «Modernidad y simulacro. La planificación moral y estética de las mujeres en la España del Desarrollo» en Concepción Campos Luque y $\mathrm{M}^{\mathrm{a}}$ José González Castillejo (coords.): Mujeres y Dictaduras en Europa y América. El largo camino, Málaga, Atenea-Universidad, 1996, pp. 149-174.

6. Para este debate, remito a DE KADT, Emanuel: Turismo: ¿Pasaporte al Desarrollo? Perspectivas sobre los efectos sociales y culturales del turismo en los países en vías de desarrollo, Madrid, Endymión, 1991, pp. 112-113.

7. Carbayo Abengozar, Mercedes: «Modernas y posmodernas: De Juanita Reina a Martirio en la búsqueda de prototipos femeninos para el siglo XX», en Amparo Quiles Faz y Teresa Sauret Guerrero (coords.): Prototipos e imágenes de la mujer en los siglos XIX y XX, Málaga, Atenea-Universidad, 2002, pp. 151-173.

8. Ver SÁnchez López, Rosario: Mujer española, una sombra de destino en lo universal. Trayectoria histórica de Sección Femenina de Falange (1934-1977), Murcia, Universidad de Murcia, 1990. Amador, Pilar: «Pequeñas reglas de convivencia social. Una aportación al estudio de la mujer durante el régimen de Franco", en Virginia Maquieira (coord.): Mujeres y hombres en la formación del pensamiento occidental. VII Jornadas de Investigación Interdisciplinaria sobre la mujer, Madrid, Universidad Autónoma de Madrid, 1989, pp. 367-384. Gallego, Ma Teresa: Mujer, Falange, Franquismo, Madrid, Taurus, 1983; Molinero, Carmen: «Mujer, Franquismo, Fascismo. La clausura forzada de un «mundo pequeño", Historia Social, 30 (1998), pp. 97-117. 
dependen de un reconocimiento instantáneo, que recuerde estereotipos familiares, bien definidos para crear el contexto del mensaje»" gracias a una estructura de referencia común y un conjunto también común de símbolos, pues cultura y comunicación se entrelazan con el fin de hacernos interiorizar la totalidad de procesos de socialización del individuo en su grupo, y de los grupos en socie$\operatorname{dad}^{10}$.

Hilvanando, pues, esta vertiente de representación de los arquetipos, partimos en nuestro análisis de las premisas generales que construyen la propaganda turística, sujeta a las coordenadas psicosociales sobre las que orbitan las motivaciones del turismo de masas. En un segundo término, estudiaremos, entre el folklore y la modernidad, la comercialización de los tópicos en la Costa del Sol malagueña, para introducirnos en el universo femenino en su faceta de estampa de promoción, como núcleo de nuestros objetivos. Así, dentro de estos márgenes, intentaremos indagar sobre las variables y los escenarios en los que se enclava la utilización de la imagen de las españolas. Por último, comentaremos algunos aspectos asociados a las extranjeras como propuesta alternativa de recreo que, en ese intento de diversificación de las ofertas de ocio, delinean el contraste -aunque sólo sea dentro del parco sistema normativo de los prejuicios- entre los bajos niveles de consecución de metas sociales en un país en vías de desarrollo, con grandes desequilibrios estructurales y con una idiosincrasia política de todos conocida, frente al destello de un mundo post-industrial de normas y valores muy distintos.

\section{LA EXPORTACIÓN INVISIBLE: POLÍTICAS DE RECEPCIÓN TURÍSTICA}

Durante la década de 1960 el turismo internacional se concebía como el maná creador de empresas y multiplicador de puestos de trabajo, toda vez que constituía una gran fuente de divisas. Instaurado como fuerza para la reactivación económica de los países receptores y, por ello, casi siempre como algo positivo, se llegó a axiomatizar desde los núcleos de diseño político la correlación directa entre Turismo y Desarrollo, como señalan Estapé y Amado ${ }^{11}$. M. Figuerola resume el hallazgo de la siguiente manera: «el incremento del número de visitantes, forzosamente elevará la demanda de empleo; causará una mejor redistribución de los capitales invertidos y de la Renta Nacional; generará ingresos suplementarios para la hacienda; promoverá el desarrollo de pequeños pueblos, rincones o puntos del litoral y fomentará el crecimiento de municipios hasta entonces abandonados a un miserable designio, que no es otro que la pobreza y la frustración $»^{12}$. De su parte, el auge del turismo de masas

9. Quatter, Terence H.: Publicidad y democracia en la sociedad de masas, Barcelona, Paidos, 1994, p. 98.

10. MuÑoz, Blanca: «El género en los espacios públicos de comunicación», en Constanza Tobío y Concha Denche (eds.): El espacio según el género ¿un uso diferencial?, Madrid, Dirección General de la Mujer-Universidad Carlos III, 1995, pp. 142-170.

11. Estapé, Fabián y Amado, Mercè: «Realidad y propaganda de la Planificación indicativa en España», en Josep Fontana (ed.): España bajo el franquismo, Barcelona, Crítica, 2000, p. 214 y ss.

12. Figuerola, Manuel: Teoría económica del turismo, Madrid, Alianza, 1985, p. 35. 
constituía un reflejo de las transformaciones socio-económicas operadas por las sociedades más industrializadas a partir de la II Guerra Mundial, estableciendo una de las líneas más relevantes de las manifestaciones del creciente consumo masificado.

A estas concepciones contribuía la facilidad que suponía depender fundamentalmente de recursos naturales - dentro de los cuales España era "pródiga en dádivas de paisaje, clima y luz» ${ }^{13}$ - que estaban en el lugar y, por tanto, no requerían de grandes inversiones, frente a otros sectores de producción. Ampliando estos conceptos, la oferta básica de un país, superadas las condiciones físicas, puede resumirse en las vertientes adicionales que aportan la infraestructura humana y la positiva (hospedajes, restaurantes, espectáculos, monumentos históricos, etc.). Nos interesará sobre todo la primera que, como apuntaba J.J. Santa-Pinter, "comprende los aspectos humanos, culturales, educativos, sociológicos, económicos y políticos, así como orden público y servicios públicos» ${ }^{14}$. Desde estos parámetros, la política pública del régimen implicó la puesta en marcha de múltiples actividades e intervenciones del Gobierno en la gestión y promoción de este sector económico, si no descubierto, redescubierto como vía básica del desarrollo, auspiciado por el Ministerio de Información y Turismo en su segunda etapa -entre 1962 y 1969-, con Manuel Fraga a la cabeza ${ }^{15}$.

Esta orientación, pretendidamente vital no sólo para la buena marcha de la economía sino también para asentar la presencia del franquismo en el mapa político occidental, se surtió de los discursos sobre la bondad de la expansión del turismo como vía para el entendimiento, esgrimido por agencias e instituciones internacionales, con lemas como A la paz mundial por el viaje alrededor del mundo adoptado por la compañía Hilton, dándole, en fin, un "sentido espiritual más hondo para así hacer de él un lazo y una encrucijada de identificación entre todos los pueblos y todas las razas ${ }^{\circledR 6}$. Así, la Conferencia de 1963 de las Naciones Unidas sobre el Viaje Internacional y el Turismo lo había proclamado como ennoblecedor y ensanchador de horizontes. También la Unión Internacional de Organizaciones Oficiales de Viajes lo definía como «una de las más deseables actividades humanas, merecedora del elogio y del favor de todos los pueblos y gobiernos». En resumen, «desde los más idealistas a los más mundanos, todos están intrincadamente atrapados en la imaginería del turismo» ${ }^{17}$. Sin embargo, pese a toda esta retórica, la realidad se ha mostrado distinta en cuanto a los resultados. De un extremo, las élites locales han venido acaparando gran parte de las riquezas que ha generado el sector, lejos de las aspiraciones de las clases más

13. Jú́rez UGEnA, Julián: «El turismo y los valores humanos», Estudios Turísticos, 38 (1973), p. 59.

14. SAnta-Pinter, J.J.: "Conciencia turística», Estudios Turísticos, 30 (1971), p. 90.

15. Fernández Fuster, Luis: Historia general del turismo de masas, Madrid, Alianza, 1991, pp. 829-848. Ver Moradiellos, Enrique: Historia de España. Tercer Milenio. La España de Franco. Política y Sociedad, Madrid, Síntesis, 2000.

16. JúREZ UGENA, Julián: Op. cit., pp. 63-64.

17. CRICK, Malcolm: «Representaciones del turismo internacional en las Ciencias Sociales: Sol, Sexo, Paisajes, Ahorros y Servilismos», en Francisco Jurado (comp.): Los mitos del turismo, Madrid, Endymión, 1992, p. 374. 
desfavorecidas, reforzando incluso los desequilibrios estructurales y los patrones económicos existentes. Crick lo expresa de modo taxativo con una simple comparación: los beneficios del turismo a diferencia del agua, tienden a fluir hacia arriba. Tampoco estimula el empleo en la medida esperada, toda vez que la mayoría de los puestos de trabajo requeridos son sin cualificar, produciendo en muchos casos lo que se ha dado en llamar escuelas de lacayos ${ }^{18}$.

Asimismo, el tema de la paz y el entendimiento terminó por desenmascararse como simple retórica que ocultaba los intereses de los especuladores. Esta actividad, en el orden del intercambio de valores entre poblaciones visitantes y receptoras, vino a instaurar islas en las localidades turísticas en las cuales el derroche y la opulencia contrastaban con la miseria autóctona, introduciendo los comportamientos de una sociedad despilfarradora en una sociedad de escasez. Un encuentro que, cuando se produjo, en muchos casos en lugar de quebrar estereotipos obsoletos los perpetuaron y reforzaron ${ }^{19}$.

Fiel en gran medida a este contexto, desde finales de los años cincuenta, las playas olvidadas de la zona occidental de la provincia malagueña reciben

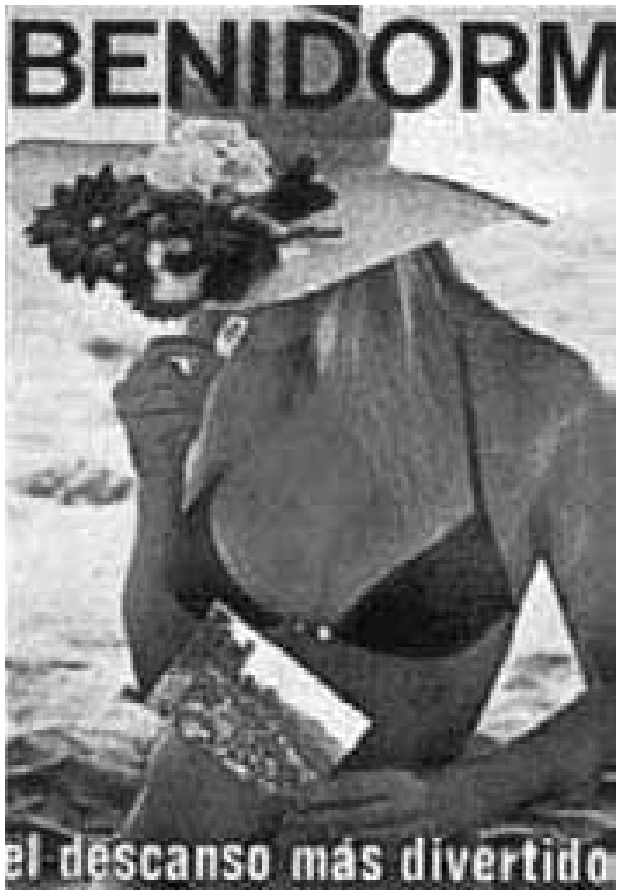

Las «nuevas valkirias» «oleadas de criaturas rubias, altas, de extraño lenguaje para los nativos que boquiabiertos las contemplan $»^{20}$. Torremolinos da el primer aldabonazo en Europa y el nombre Costa del Sol se lanza al mercado internacional, donde, si bien no se puede vender la pobreza, se puede vender el paraíso ${ }^{21}$.

Vistos estos datos, el estudio del fenómeno turístico implica y requiere, básicamente, la profundización en el estudio de la creación de mitos disfrazados de realidades, supeditadas inexorablemente a los requerimientos de una cultura de consumo de imágenes. En este círculo, las necesidades del turismo de masas, su caracterización y función psicológica tienen mucho que mostrar para entender los presupuestos de partida de cualquier política de recepción turística.

18. Ibíd., pp. 356-357.

19. Gracia García, Jordi y Ruíz Carnicer, Miguel Ángel: Historia de España. Tercer Milenio. La España de Franco. 1939-1975. Cultura y vida cotidiana, Madrid, Síntesis, 2001.

20. JRDAO, Francisco: España en venta, Madrid, Endymión, 1990, p. 137.

21. Esteve Secall, Rafael: Ocio, turismo y hoteles en la Costa del Sol, Málaga, Universidad de Málaga, 1982. 


\subsection{Funciones y elementos de las vacaciones y razones del turista}

Desde el escenario que acabamos de esbozar podríamos sintetizar en pocas palabras la motivación turística, así como las funciones psicológicas básicas que cubre la realización del viaje. Para empezar, la necesidad de cambio, la huida del trabajo diario, de las rutinas cotidianas y del propio entorno que las rodea, parece constituir un factor común a toda iniciativa, así como el prurito de relajarse y divertirse acompaña -explícita o implícitamente- a cualquier turista, atendiendo recíprocamente a un deseo de descanso, sobre todo en su polémica faceta de evasión ${ }^{22}$. La máxima de T.S. Eliot sobre el hecho de que los seres humanos no pueden soportar demasiada realidad encaja bien en esta esfera. En la línea de este concepto, como en general el tiempo de ocio, las vacaciones se presentan en una doble vertiente. Por una parte se perfila un mundo de libertad, de paraíso - a lo cual aluden las teorías de Dumazedier, Krippendof o Jafari-, de realización mítica. Sin embargo, cuando nos adentramos en su análisis vemos que el ocio también es consumo y alienación, en base a la perspectiva crítica mantenida por Marcuse, Fromm, Adorno, Turner, Asj y MacCannell, entre otros ${ }^{23}$.

Desde el primer punto de vista, A. Robles apunta que la actitud turística universal consiste en «el placer presentido, la pura premonición de la felicidad $»^{24}$, puesto que la inicial disposición del turista es de fiesta y liberación, refrendada por las representaciones colectivas de turismo internacional que se utilizan normalmente en las Ciencias Sociales, conocidas con frecuencia como las 'Cuatro S': sun (sol), sex (sexo), sea (mar) y sand (arena) ${ }^{25}$. En su línea, la publicidad ha captado estos componentes mostrando gentes disfrutando de esa transitoria libertad, "con alegres vestidos, sobre fondos de terrazas de muebles ligeros o ninfas modernas saliendo del mar en ágil carrera, hacia sombrillas

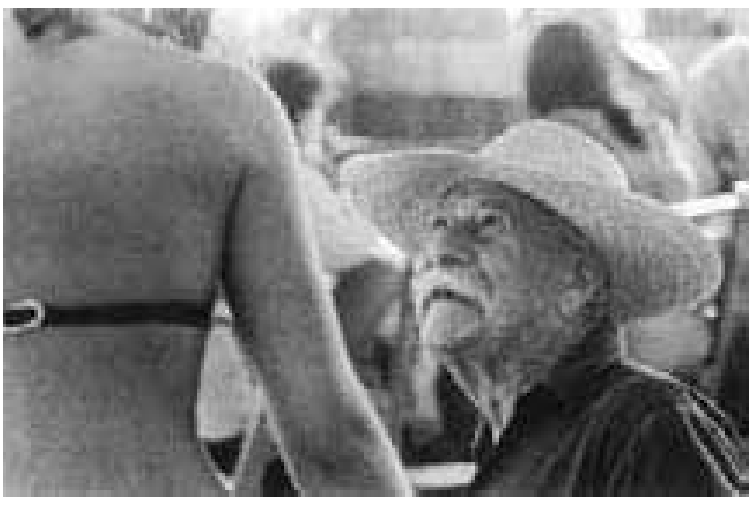

Estética y ética del «bikini» rutilantes ${ }^{26}$.

El individuo en vacaciones, en fin, necesita y cree entregarse a un tipo de vida muy distinta de la que hace el resto del año. Así, básicamente, como propone González Seara, surge ese nuevo y extraño animal dotado de cámara fotográfica o tomavistas, para, ya de vuelta, poder decir "yo estuve aquí y

22. Ortíz de Mendivil, Juan: "Ocio y Turismo», Estudios Turísticos, 38 (1973), p. 31.

23. Ver Álvarez SousA, Antonio: El ocio turístico en las sociedades industriales avanzadas, Barcelona, Bosch, 1994.

24. Robles Álvarez de Sotomayor, Alfredo: "Ocio y Turismo", Estudios Turísticos, 12 (1966), p. 94.

25. CRICK, Malcolm: Op. cit., p.343.

26. Robles Álvarez de Sotomayor, Alfredo: Op. cit., p. 94. 
allá», sin haber visto realmente lo que ha fotografiado con la "enorme seguridad que le proporcionan los documentos notariales de su cámara » ${ }^{27}$. El bronceado es también una prueba documental de que se ha estado de vacaciones y si, además, se regresa bastante demacrado, la estimación de los demás será mayor, "porque indicará claramente que uno se ha divertido» ${ }^{28}$. La pintura de sus jornadas discurre, pues, en la playa donde "contempla, unos momentos, a una chica que toma el sol», con alguna excursión o visita a los lugares de atracción típica y salidas nocturnas que completan el periplo ${ }^{29}$. Si, en definitiva, advierte Mings, el turismo se perfila entre dos mitos extremos -regalo de los dioses y forma endemoniada ${ }^{30}$-, en nuestro país, el franquismo vivió la recepción de viajeros con entusiasmo, pretendiendo contentar y arropar con el espíritu de la península a todo el que se bañaba en él, limpiando de males al visitante y, de cara al interior, exorcizando cualquier influencia perniciosa para el statu quo social.

\subsection{El souvenir, lo típico y la comercialización: los estereotipos en la Costa del Sol}

Frente a lo dicho, la búsqueda y el diseño de bienes, con carácter absolutamente turístico, constituye una prioridad. Si bien la imagen de España, descrita por F. Ayala como una Bella Durmiente, introduce la reacción de los extranjeros en una doble vía - «furor ante lo inerte e inmanejable» de un lado, y "delicia innegable» que "hace olvidar las asperezas, suciedades y demás prosaísmos de un mundo industrial», del otro ${ }^{31}-$, su anacronismo práctico construye una buena oferta de cara al sector como "ósmosis vital y cultural»"

Dado que el turismo, en su faceta de exploración histórica y étnica, indaga sobre las tradiciones de un pueblo y su carácter, estos serán presentados, al unísono con los paisajes, como los grandes protagonistas de la búsqueda del viajero en vacaciones. Sin embargo, la demanda de la sociedad opulenta occidental, el proceso de convivencia de sistemas de valores distintos que imponía las miradas, los procesos de creación y de recreación de experiencias, orientan la venta indiscriminada de escenarios de cartón piedra, de los que se extirpa todo aquello que no es agradable al esquema normativo de la sociedad post-industrial. Así, toda vez que se oferta el Edén perdido, conservado para el divertimento y descanso del turista, aquél, como un espejo, refleja la mirada satisfecha de los logros del Desarrollo ${ }^{33}$.

27. González Seara, Luis: «Las vacaciones del español y el problema del tiempo libre», Revista Española de Opinión Pública, 14 (1968), p. 47.

28. Ibíd.

29. Ibíd., p. 55.

30. MNGS, R.C.: "The importante of more research on the impacts of tourism», Ann.Tourism Res., 5 (1978), p. 343.

31. Ayala, Francisco: La imagen de España. Continuidad y cambio en la sociedad española (Papeles para un curso), Madrid, Alianza, 1986, p. 43.

32. Sur, 30 de abril de 1965 , p. 7.

33. EORES, Edmundo: Dentro y fuera del Desarrollo, México, FCE, 1973. 
Fiel a estos presupuestos, el tópico como objeto comercial se disfraza con el marchamo de calidad de lo auténtico, de lo real, desterrando «todo lo que de sucio o denigrante puede haber que, afortunadamente es lo más escaso: el pordiosero, el limpiabotas, el ocioso y gandul, el borracho» ${ }^{34}$, en el marco de un hedonismo que demanda -paga- placeres y desinhibiciones. En este sentido, la cultura deviene en "souvenir», como "artículo de recuerdo", no sólo en su faceta de bien material que puede ser adquirido en las tiendas, sino como todo aquel cúmulo de experiencias vividas o recreadas para el consumo, a fin de que el visitante disponga de una nueva satisfacción adicional en su retorno, como postal de la memoria. La felicidad, pues, se torna y crece a partir de la alienación de la cultura, empaquetada "por el precio correspondiente, para terminar por venderse tal como se venden los terrenos, los derechos de paso, la comida basura y el servicio de habitaciones, a medida que la industria del turismo inexorablemente abarca más y más» ${ }^{35}$.

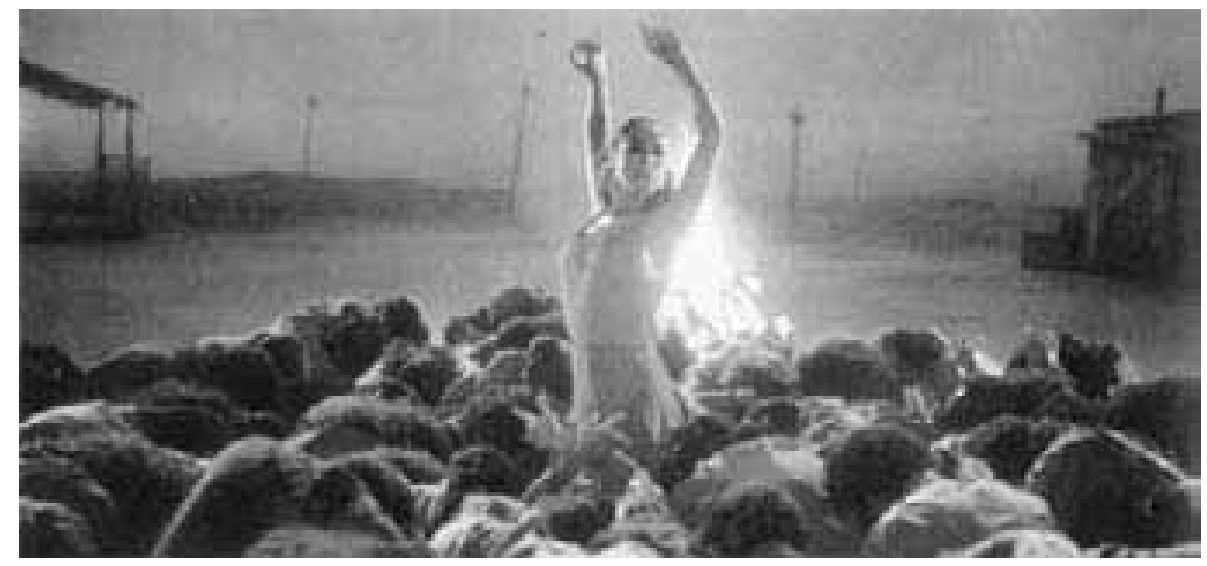

Bailaoras flamencas: las eternas «Cármenes»

En nuestro caso, en definitiva, se mercantiliza una imagen del progreso donde la satisfacción en todos los órdenes conjuga crecimiento económico y equilibrio social. Todo ello fusionado por la asunción de la tecnología y sus nuevos valores, conservando simultáneamente una tradición que en su faceta de solera filosófica "puede beneficiar a toda la humanidad» ${ }^{36}$, dentro de los parámetros de un renacimiento espiritual que sólo se entendía a partir de la plataforma política creada por la ubérrima Paz de Franco. Ésta había recuperado para España y para el mundo un paraíso tradicional y, a la vez, había puesto las bases de una peculiar modernización, en la cual el folklore, la fiesta, el descanso, seguían

34. Sur, 23 de octubre de 1965, p.15.

35. GREenwood, David J.: "La cultura al peso: perspectiva antropológica del turismo en tanto proceso de mercantilización cultural", en Valene L. Smith (coord.): Op. cit., p. 269.

36. Sur, 17 de septiembre de 1965, p. 3. 
ocupando un papel central. La revista del Sindicato Provincial de la Alimentación publicaba en 1964 un escrito que condensa los beneficios devengados para los trabajadores por el Plan de Desarrollo: «El español está ahora/ mejor que nunca en su vida;/ trabaja reloj en mano/ y su hora se cotiza,/ y sus sudores no tienen angustias de hambre maldita./ Sus angustias están en la tele/ cuando 'El Cordobés' cita./Viva el Plan de Desarrollo y vivan toas las turistas ${ }^{37}$.

Así, la estrategia en la construcción de un modelo turístico, por otra parte nada novedoso, tejía "españolismo y modernidad»" en una línea resumida, diáfanamente, por el espectáculo ofrecido en una sala de fiestas de la Costa del Sol, cuyo programa aúna un ballet racial con «bailes y canciones de la vieja España y los reyes del twist: Los Diablos ${ }^{39}$.

Se propone «la vida con todo el poder de su sabor" y los andaluces, en este caso en Benalmádena, gozan de un reposo que "aquí era completo» ${ }^{40}$. Desde este escenario, un artículo de opinión de 1964 expone las variables de ese fresco de realidades malagueñas a través de una triple caracterización definidora de entornos interconectados, en los que se mueve el estereotipo de

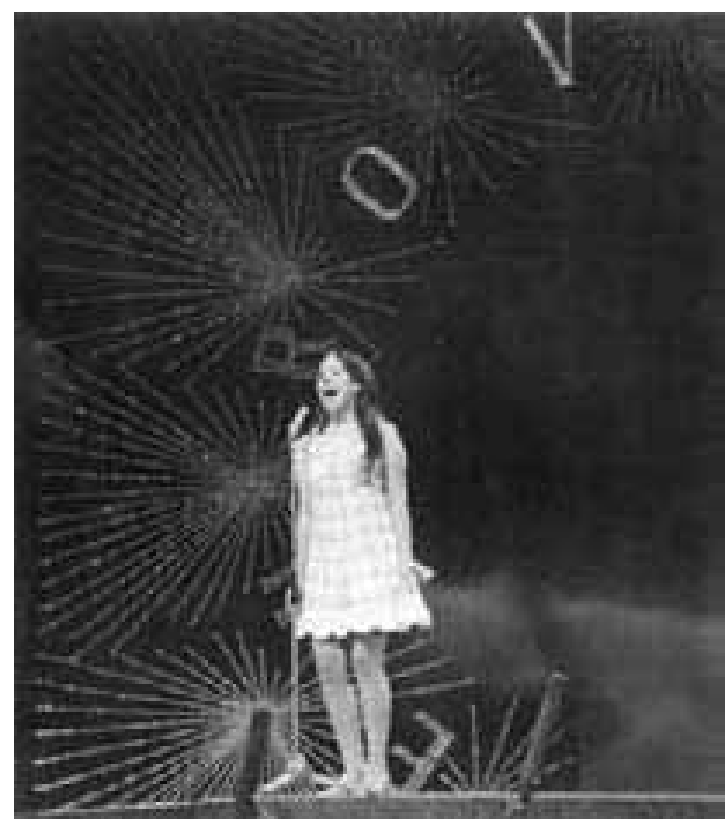

La chica española «ye-ye» la provincia. Por un lado, la "Málaga cantaora» de Machado, de los momentos de preguerra, espejo romántico, ácrata y "ferozmente individualista» ${ }^{41}$, que dio paso a lo que podríamos llamar con W. E. Moore, "ciclo de pecado y penitencia $»^{42}$. En este marco cronológico, moralizante, de los años cuarenta y cincuenta, la «sociología de la privación»" engendraba los "Veinticinco años de Paz». Era el tiempo de una "Málaga intermedia, que vivía la grata pausa de sus jornadas». Un tercer estrato, el del

37. Ver ASPA (Málaga), 2 (1964), p. 4.

38. ABellán, José Luis: La cultura en España, Madrid, Edicusa, 1971, p.80.

39. Sur, 28 de febrero de 1964, p. 5.

40. Sur, 22 de octubre de 1964, p. 7.

41. Sur, 19 de enero de 1964, p. 7.

42. MOore, Wilbert E.: "Organización y cambio», en Robert Nisbet y otros: Cambio social, Madrid, Alianza, 1979, p.82.

43. ABella, Rafael: Op .cit., p.105. 
presente, el de los años sesenta, definía la «maraña neomalagueña» de "excesiva sonoridad $\aleph^{44}$, donde todo es siempre cambiante $\mathrm{y}$ original.

Efectivamente, el espíritu de una Málaga eterna - "Málaga entera, intemporal y eterna'- se enfrentaba en esta coyuntura con la idea de "una ciudad donde todo ha de ser siempre tan nuevo» ${ }^{45}$, con base, como ya apuntábamos, en el código contemporáneo de lo efímero impuesto por el hedonismo radical del que hablan Marcuse y Fromm. En este terreno, el concepto de integracióndesintegración como variable de la sociedad moderna cobra sentido ${ }^{46}$, construyendo un estilo de vida en el que lo viejo y lo nuevo interactúan para conformar una estructura perfecta, propagandística, en función de una serie de factores: paz, orden y felicidad, de un lado y, de otro, espíritu cosmopolita y de progreso, celoso sin embargo de la preservación de lo tradicional.

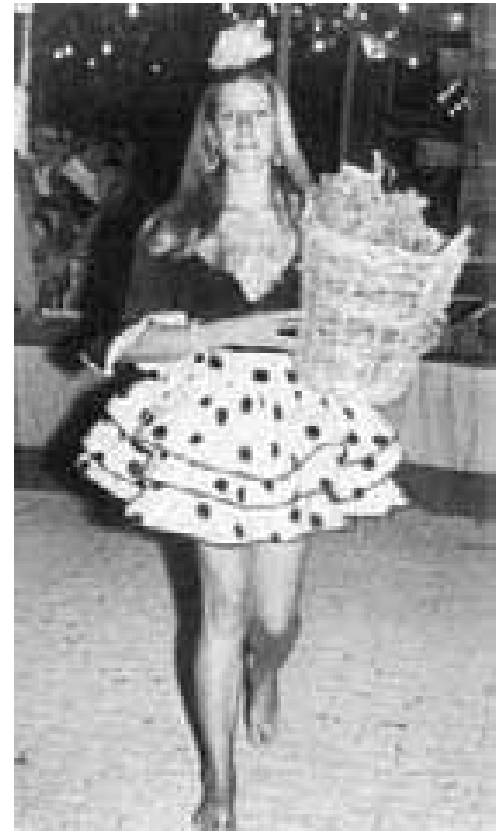

El folklore puesto al día

Esta situación, en muchos sentidos contradictoria, intenta explotar códigos, valores y normas en gran medida divergentes, compilando lo más inocuo de cada uno para mantener demagógicamente el ajuste social, capitalizando -en el terreno que analizamos- la fórmula del modo de ser hispano, inmanente y a la vez abierto a todas las modas, como terapia vacacional. En última instancia, los términos de la oferta y la demanda exhiben al país como inmenso balneario que tiene en nuestra provincia la capital del «Mercado Común del Usted lo Pase Bien " $^{7}$. Por esta vía, los títulos de "Muy Hospitalaria» $\mathrm{y}$ "Muy Benéfica» -para las enfermedades cardiovasculares, por ejemplo-, adquieren una nueva dimensión como valor de cambio turístico, expandiendo el genio andaluz al son que marcan las divisas de una «Europa fatigada, seria, nerviosa, adusta y preocupada ${ }^{48}$. Dentro de esta onda, a la Málaga tradicional y la Málaga moderna les corresponderán sendos modelos femeninos -en los que indagaremos más tarde- conectados directamente con el relevo generacional, y muy comerciales y explícitos a la hora de narrar la idiosincrasia cultural y social del régimen. En su construcción, siguiendo los patrones de la cultura de masas, «los valores que se definen como estrictamente femeninos, entre los cuales se

44. Sur, 19 de enero de 1964, p. 7.

45. Sur, 22 de octubre de 1964, p. 20 y 8 de noviembre de 1966, p. 2.

46. Iefebvre, Henri: La vida cotidiana en el mundo moderno, Madrid, Alianza, 1982, p. 222.

47. Sur, 30 de agosto de 1966, p. 7.

48. Sur, 27 y 30 de agosto de 1965 , pp. 15 y 7 respectivamente. 
hallan la individualidad, el bienestar, el amor, la felicidad, representados en la iconografía» se funden, en líneas generales, "en la reunificación de dos términos tradicionalmente irreconciliables: la vamp y la virgen ${ }^{49}$.

Asimismo, el toque final para llevar a buen puerto el desarrollo de la naciente industria consistía en fomentar la instrucción de españolas y españoles en este sentido, no sólo como obligación contraída con el lanzamiento económico sino, pretendidamente, como prurito moral de servicio a la humanidad. Además de edificar hoteles y fortalecer todas las infraestructuras del sector, era preciso crear una conciencia turística a través de la cual cada malagueño se convertía en un jefe de relaciones públicas ${ }^{50}$. Desde estos supuestos, la representación de su estampa se explota publicitariamente hasta una saciedad de la que aún somos esclavos, resultando un aliciente eficaz frente a una propaganda excesivamente centrada en las excelencias del tiempo atmosférico. El franquismo demostró que la proclamación y la promoción de fórmulas originales no se agotaban ahí. Por supuesto, la peculiaridad del ser malagueño era única y el calor del sol no.

\section{ANFITRIONES Y HUÉSPEDES: EL UNIVERSO FEMENINO COMO ESTAMPA DE PROMOCIÓN}

H. Lefebvre, entre otros, define la capitalización de la imagen femenina en distintos planos de realidad como uno de los caracteres del mundo contemporáneo, siempre en función de su utilidad referida a campos de acción social, política o económica. Así, en un sentido amplio, se dibujará a las mujeres como producto de consumo ${ }^{51}$, de un lado, y como consumidora, de otro, a instancias del lugar central que ocupan en la gestión de la esfera privada. Desde su seno, la modernidad «se traduce en implicar un manejo más competente de una mayor variedad de bienes", presentando al ama de casa como "GPA» (General Purchasing Agent, Agente General de Compras), a partir de una analogía entre el hogar y una empresa con la esposa como director ${ }^{52}$.

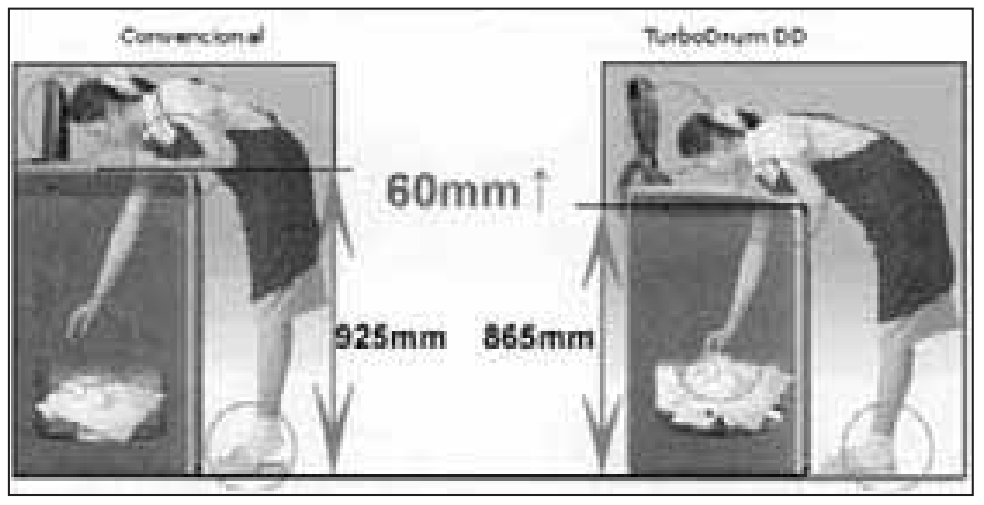

Un toque de modernidad en la publicidad: las lavadoras

49. Vera Balanza, Ma Teresa (ed.): Mujer, cultura y comunicación. Entre la Historia y la sociedad contemporánea, Málaga, Málaga Digital, 1998, p. 9.

50. Sur, 13 de febrero de 1966, p.15.

51. Iefebvre, Henri: Op. cit., p. 210.

52. Qualter, Terence H.: Op. cit, p. 104. 
En cualquier caso, el arquetipo moderno se seguirá construyendo bajo la autodisciplina moral y estética, en una carrera constante que implica ganar feminidad y, para ello, "hay que saber andar, sonreír, hablar, hacer gestos... si supera los defectos que tenga cualquier mujer poseerá charme y vivirá contenta y optimista.... ${ }^{53}$. Sin embargo, aquí está la diferencia entre las españolas y las extranjeras, la mini-falda no tiene porqué implicar la asunción de una minimoral, según se apunta en un artículo del diario Sur ${ }^{44}$. Si España es diferente, lo es por su integridad, su sobriedad, espíritu de servicio y, además, por su hospitalidad y desparpajo, entre los límites de un pasado romantizado y un futuro predominantemente conservador. Si esto era así, la mujer española y, sobre todo, la andaluza, venía a configurar el eslogan vivo de cualquier campaña turística. Las extranjeras, como decíamos en el apartado inicial, constituían la seña de que nuestro país estaba dispuesto a recibir nuevas influencias tal y como, de una manera cosmética, quería mostrarlo el franquismo en el entorno internacional, trazando a través de su fisonomía ofertas alternativas de un ocio más cosmopolita ${ }^{55}$.

\subsection{Las biografías de la mujer española. El status socioeconómico y los márgenes de visibilidad}

Superado el espectro amplio que hemos esbozado, como en tantos otros terrenos de análisis, el estudio de la utilización de los arquetipos femeninos a efectos publicitarios debe empezar por desagregar las diferencias introducidas por el status socio-económico. Si bien la edad perfila un sesgo importante en la disección de comportamientos, normas y valores, la situación socio-económica constituye la variable de control que sin duda marca la comercialización de la imagen de la mujer en la política del sector, instituyendo, en definitiva, modelos de conducta según la posición en las relaciones de clase.

En conjunto, las variables de las que hablábamos determinan la naturaleza del tipo de encuentro, en función del ámbito en el que se desarrollan. Como manifiesta E. De Kadt, las relaciones entre invitados y anfitriones se producen en tres contextos principales: donde el turista está comprando algún bien o servicio, donde el visitante y el anfitrión se encuentran el uno al lado del otro, por ejemplo en una playa o en un espectáculo nocturno, y donde ambas partes se encuentran cara a cara con objeto de intercambiar información o ideas ${ }^{56}$.

Dentro de estos márgenes, los perfiles matizados por la posición social, directamente hilados a la situación laboral, constituirán los márgenes de presencia en el eslogan publicitario de la Costa del Sol. Así, en una proporción inversa, las mujeres que ocupan los estratos medios e inferiores serán las más visibles, las más útiles en la representación de los logros y beneficios del modo de vida

53. Sur, 22 de mayo de 1966, p. 12.

54. Sur, 10 de julio de 1966, p. 12.

55. Comitre, Isabel: «Publicidad e imagen de la mujer en Francia y España», en $M^{a}$ Teresa Vera (ed.): Op. cit., pp. 40-43.

56. DE KADT, Emanuel: Op. cit., p. 95. 
hispano, toda vez que ellas son las llamadas a decorar plazas y mercados y a establecer las relaciones comerciales cotidianas con el turista. Desde un primer acercamiento al tema es claro que los estratos populares, en una versión del tipismo para el caso de las mujeres de mayor edad, curtidas por la supervivencia de posguerra, y sus hijas -el más grande hallazgo de los favores del crecimiento económico- darán forma a los iconos de la política franquista como el antes y el después de una fotografía en la cual ambos modelos, diferentes y a la vez compatibles, gozan de la misma simpatía.

Las mujeres que componen las clases altas -lejos del bullir de la calle- se mantendrán, pues, o bien ajenas a los intercambios con los visitantes o bien, como integrantes de las élites locales, se relacionarán con ellos en un plano de mayor igualdad, identificándose con el estilo de vida y con el atractivo snob de los turistas, puesto que así ellas mismas pueden formar parte de la «jet set internacional $\aleph^{57}$, ejerciendo, en definitiva, un rol de clase que da cuerpo a la teoría del consumo ostentatorio, enunciada por $\mathrm{T}$. Veblen a finales del siglo XIX. En esta misma línea, sus hijas, que también gozan de la oportunidad de ese contacto en clubes y otros sitios de recreo y esparcimiento, se muestran aún más receptivas a la influencia modernizadora ejercida potencialmente por el turismo, acercándose, dentro de unos límites en cualquier caso, a sus normas y valores, movidas por la curiosidad y el deseo de emulación.

\subsection{La explotación de los arquetipos populares. Entre el folklore y la modernidad}

Frente a ellas, como apuntábamos en primer término, la mujer de extracción popular -sobre todo la que desempeña un trabajo fuera del hogar-vive la relación con el turista siempre en función y en el contexto de la prestación de algún servicio, trasladando así ciertas relaciones humanas a la esfera económica, puesto que la comunicación que escapa a este ámbito "cuenta para sólo una parte marginal de toda la experiencia ${ }^{58}$.

En general, como ornato de la Costa del Sol, ofrecen una alternativa ideológica y estética a la sociedad impersonal, mostrando lo que florece bajo el sol gracias a la luz encantada de un país de nunca jamás. Dentro de este marco, las mujeres de mayor edad condensarán el gran eje del tipismo y la encarnación de la tradición popular, por sus oficios y sus modos de ser y vivir, felices de mostrar su peculiar cultura de la pobreza, orlada con dignidad y alegría. Todos esos valores se resumen en una vecina de Torremolinos, «una mujer de gran carácter, pero sencilla, afable» que "en sus decisiones, sin embargo, es tajante y destaca en ella un acusado sentido de la honradez y la caridad", y de un "espíritu noble» que «sabe ganarse fácilmente la amistad de todas aquellas personas con las que

57. CRICK, Malcolm: Op. cit., p. 368.

58. De KaDt, Emanuel: Op. cit., p. 110. Cf. Martínez, Rosalía: «Publicidad y roles de género. Reflexiones sobre el trabajo de las mujeres y su acceso a la vida pública», en $\mathrm{M}^{\mathrm{a}}$ Teresa Vera (ed.): Op. cit., pp. 47-50. 
trata ${ }^{59}$. Así, dándole nombre a una calle de la zona, esta vecina es elevada a icono como perfecta promotora turística.

Desde la misma perspectiva, los usos y costumbres femeninos, ya lo decíamos, constituyen un elemento ineludible del universo del souvenir hispano. Una mujer que borda en la puerta de su casa da forma a una impagable alegoría de aquella Andalucía eterna, donde los relojes se han esfumado, "y ésta, en fin, es una estampa clásica de cualquier pueblo de la costa y forma parte de su acusada personalidad ${ }^{60}$. Como el reverso de la moneda que ofrecen sus madres, las jóvenes que se incorporan al sector servicios desempeñan una variedad de trabajos entre los cuales las autoridades destacan los más llamativos para construir la efigie de una Málaga cambiante en la que todo constantemente se renueva ${ }^{61}$. En esta línea, la prensa local en 1964 se hace eco de un rasgo atractivo de los autobuses de Fuengirola consistente en emplear a "chicas agraciadas para cobrar los inevitables billetes ${ }^{62}$. Ellas, como estampas publicitarias que encarnan el prototipo surgido de la planificación del Desarrollo, perfilan la imagen de España en circuitos donde la libertad y las cotas de igualdad obtenidas son el producto de una mayoría de edad auspiciada por el Estado. Juveniles, alegres, desenvueltas, dinámicas y deportivas serán los adjetivos recurrentes que se les asocian, todo ello resumido en una sola palabra: modernas. Pero en nuestro ámbito ¿qué conllevaba el concepto?

Puesto que «las naciones más adelantadas y civilizadas son aquellas en que, en el buen sentido de la palabra, la mujer goza de mayor libertad y participación en toda clase de actividades», ellas simbolizan los logros devengados del franquismo, aunque «no nos pase que las españolas quieran equipararse a sus congéneres europeas; dejemos que nuestras niñas hagan deporte, bailen, aprendan muchas asignaturas y se calcen sus pantaloncitos ${ }^{63}$, instándolas, por otra parte, a seguir luchando, "porque el mundo lucha también para destruir lo que vosotras representáis, para traernos un materialismo capaz de transformar la conciencia de la mujer, tal y como la concebimos los españoles» ${ }^{64}$.

Libertad, pues, en el acceso a distintos espacios -aún muy reducidos y teóricos- como sinónimo de preparación para hacer compatibles diversas tareas en base a la ampliación progresiva de la doble jornada, la cual abarca, todos los dominios de la vida de la mujer moderna: "gobierno de la casa, la profesión, las horas libres, la moda y la cosmética, la técnica y el trabajo artesanal en el propio hogar» ${ }^{65}$. Sin embargo, el trabajo doméstico, al que se sacrifican tantas horas, seguía ocupando la mayor parte del universo femenino, aunque éste no es fácil

59. Sur, 22 de febrero de 1964, p. 7.

60. Sur, 25 de febrero de 1964, p. 7.

61. Domenech, $M^{a}$ Carmen; Mate, Milagros y Visso, Elena del: «La mujer y el trabajo en la Costa del Sol occidental», en $\mathrm{M}^{a}$ Dolores Ramos y $\mathrm{M}^{\mathrm{a}}$ Teresa Vera (eds.): Op. cit., pp. 167-176.

62. Sur, 25 de febrero de 1964, p. 7.

63. Sur, 31 de diciembre de 1965, p. 20.

64. Sur, 24 de enero de 1964, p. 17.

65. Sur, 22 de octubre de 1965, p. 2. Ver Romo ParRa, Carmen: «Tiempo de trabajos...», Op. cit., pp. $55-81$. 
de medir, como demuestran las Encuestas del Instituto de Opinión Pública y los Informes de la Fundación Foessa ${ }^{66}$. Pese a ello, dentro de este contexto, la adquisición hipotética de igualdad en el reparto de tareas también se esgrime con fuerza en el discurso modernizador, toda vez que, en realidad, sólo de forma incipiente se empieza a abrir a las mujeres la posibilidad de desempeñar un trabajo remunerado, donde, por otra parte, se sostiene la dicotomía entre profesiones tradicionalmente femeninas y trabajos específicamente masculinos ${ }^{67}$.

Pero ¿qué hay realmente nuevo en estos perfiles? La «libertad de la mujer» como peculiaridad central, por encima de la igualdad, insiste básicamente en una concepción del dinamismo remitido a la "afición a los deportes» ${ }^{68}$, así como a otras actividades igualmente inocuas para el desarrollo de un mayor protagonismo social, girando, desde otro extremo, alrededor de una capacidad de adaptación a todo tipo de cambios en un sentido de búsqueda de lo original, en términos superficiales. Una libertad explicada y expandida sobre todo en el mundo de la publicidad, donde es sujeto y objeto de reclamo en la venta de prendas y demás productos de consumo personal y doméstico, y que, en último término, significa más independencia para conseguir los fines tradicionales, frente al hallazgo de libertad "para buscar otros objetivos» ${ }^{69}$.

En este sentido, en

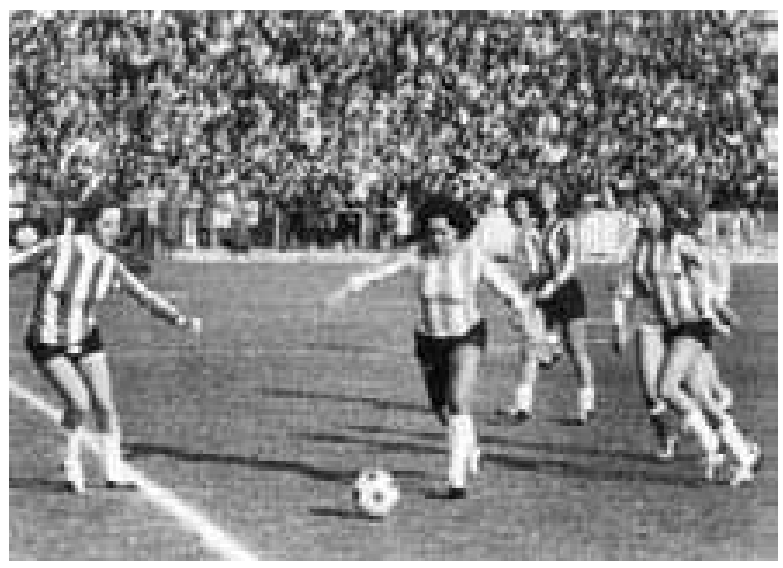

Deporte y culto al cuerpo España no sólo se mantuvo la perspectiva con respecto a las peculiaridades específicas de los sexos, sino que se redundó en la exigencia de «un tratamiento educativo peculiar en orden a su función social concreta ${ }^{70}$. La función social de la que venimos hablando

66. Instituto de la Opinión Pública: «Tiempo libre y ocio», Revista Española de la Opinión Pública, 36 (1974), p. 212 y ss. FUNDACión FOESSA: Informe sociológico sobre la situación social de España. 1970, Madrid, Euramérica, 1971.

67. Romo Parra, Carmen: «Tiempo de trabajos...», Op. cit., p. 75.

68. Sur, 19 de enero de 1964, p.12.

69. Ouatter, Terence H.: Op. cit., p. 104.

70. En este sentido se expresaba Teresa Loring, subdirectora nacional de Sección Femenina durante su intervención en la comisión del Consejo Nacional del Movimiento, en 1966. En la misma tónica, un par de años antes el vicesecretario general del Movimiento en las sesiones del XXII Consejo Nacional de Sección Femenina había apuntado que dicha institución no era sólo un instrumento de acción formativa sobre la mujer española, sino también un importante medio de influencia sobre la sociedad en su conjunto. 
convirtió a las mujeres de Sección Femenina en auténticas embajadoras del régimen con sus muestras de Coros y Danzas, según nos ha mostrado recientemente Estrella Casero ${ }^{71}$. Pero hablamos de una misión consustancial de Sección Femenina de Falange, expresada desde sus orígenes, utilizando las palabras de Pilar Amador, en "pequeñas normas de convivencia social» acordes con el modelo de feminidad dominante ${ }^{72}$. En este ámbito, la transmisión del folklore subrayaba las bellezas de la cultura popular de nuestro país a través de sus mujeres, llamando al mundo a visitarnos. Hablamos, en fin, de una cultura que se feminiza y sirve para canalizar una propaganda en la que las mujeres prestarán su imagen a postales fijas de marketing turístico, apelando a la capacidad de deleite y asombro del visitante que, a través de los sentidos, pretende llegar a tocar el resorte secreto de las respuestas emocionales.

\subsection{Turistas extranjeras y creación de un nuevo universo de ocio}

«Sentadas o tumbadas con ese modernismo despreocupado exhibían las piernas con una liberalidad semejante a la que Miguel Ángel prodigó ${ }^{73}$ : son las chicas extranjeras que visitan la costa malagueña. Desde la otra orilla, dibujan un componente esencial de la creación de un universo de ocio en el que la apertura a mundos posibles domina los ingredientes que iremos esbozando. Por un lado, su figura aglutina el aliciente de las libertades alcanzadas por la mujer occidental, a partir de las cuales se destacan los elementos estéticos más epidérmicos y lúdicos, despreciando las facetas más comprometidas con la puesta en cuestión de la moral tradicional de la mujer española, sólida, imperturbable y práctica para el sostén de los privilegios de los varones. Básicamente, las extranjeras conforman el emblema dirigido a un imaginario masculino que demanda recreo, puesto que es claro el número "de miles de jóvenes y hombres maduros que vienen aquí pensando en divertirse ${ }^{74}$, hasta situar este prototipo en el epicentro de la ruptura con el conjunto de representaciones de la cotidianidad y de las actitudes con respecto a ésta como factor fundamental de la vivencia de las vacaciones. Si, en última instancia, el viaje turístico «es un fragmento de nuestras vidas sobre el que tenemos el mayor control posible»y, por tanto, «no es de extrañar que los turistas se sientan decepcionados cuando sus fantasías, elegidas con vistas a satisfacer sus apetitos, no se realizan como ellos esperaban ${ }^{75}$, el erotismo velado apoyará el éxito de unas campañas en las cuales se intenta atraer la atención del público con estímulos que a veces tienen poca relación con el producto, «utilizando modelos femeninos provocativos y situaciones sexualmente sugestivas $»^{76}$.

71. CASERo, Estrella: La España que bailó con Franco. Coros y danzas de la Sección Femenina, Madrid, Nuevas Estructuras, 2000. La película Ronda Española, del director Ladislao Wadja, es una muestra cinematográfica de esta labor propagandística por tierras hispanoamericanas, como se analiza en otro artículo de esta revista.

72. AMADOR, Pilar: Op. cit., pp. 367-384.

73. Sur, 15 de febrero de 1964, p. 7.

74. Sur, 12 de agosto de 1964 p. 7.

75. Gaburn, Nelson H.: Op. cit., p. 55.

76. Qualter, Terence H.: Op. cit., p. 103. 
Esa horda dorada, en fin, sujeta al estereotipo en tanto que evaluación generalizada aplicable al turismo de masas y que, en el aspecto que nos interesa, muestra los hallazgos de la liberación sexual, empieza y termina con la estancia y marcha de suecas y alemanas, aunque las señas distintivas más obvias y banales del progreso -los transistores, las gafas de sol, la música pop, etc.- tienden a quedarse entre nosotros, difuminando en sus aspectos más superficiales la frontera entre España y el mundo convulso de la Guerra Fría.

Los primeros visitantes que llevaron a Torremolinos los operadores turísticos, subrayan Turner y Ash, eran un escaso grupo de gentes acomodadas que buscaban nuevos destinos, hasta que, a comienzos de los sesenta, se puso de moda a lo grande como auténtica periferia del placer. Frente al enclave más aristocrático de Marbella, se trataba, según se dijo, «de la casa y lugar predilecto de las estrellas de cine y los contrabandistas, las ricas herederas y los desheredados, los excéntricos y los efímeros de los cinco continentes» ${ }^{77}$, creando un caldo de cultivo que gesta el arquetipo masculino más mítico de todos: el play-boy.

Así, en la búsqueda de la afirmación de sus distintos atractivos, las autoridades esgrimen la creciente importancia de la Costa del Sol como importadora de novedades. El cine, por ejemplo, en su faceta más reconocible de gran ventana abierta a la visualización de los sueños, sitúa a los grandes símbolos fuera de la pantalla y los enclava en Málaga. Esta tierra, como "productora de cine»78, muestra su relevancia con la llegada de un mito sexual de la importancia de Brigitte Bardot, que rodó una película en los alrededores de Torremolinos, tal y como lo hicieron, entre muchos otros, J. P. Belmondo o G. Chaplin, hasta convertir de inmediato al lugar en el centro turístico español más cosmopolita. Insistiendo en la apuesta por ocios infantiles, también aparecen en escena las últimas tendencias en artes plásticas con la apertura de salas de exposiciones que surten una cultura de adorno donde brillan, sobre todo, las estrellas de la canción, las del deporte femenino y las misses internacionales, entre ellas Miss Montreal, que prometió hacer en 1965 "una gran propaganda de nuestra tierra» ${ }^{79}$.

Hilado al parámetro anterior, sus opiniones como invitadas sin duda cuentan mucho: ellos -y en especial ellas- también «son, a su manera, los mejores agentes de promoción turística ${ }^{80}$. Están encantadas con las temperaturas de las que gozan y sobre todo aquí se encuentra «una sana libertad como en ninguna parte del mundo" dado que, como comenta una chica respecto a Holanda, allí "se puede escribir libremente de lo que se quiera, pero nada de lo que se escribe se puede hacer» ${ }^{81}$.

77. TURner, Louis y Ash, John: La horda dorada. El turismo internacional y la periferia del placer, Madrid, Endymión, 1991, p. 145.

78. Sur, 12 de enero de 1965, p. 7.

79. Sur, 5 de enero de 1965 , p. 7.

80. Sur, 2 de enero de 1965, p.7.

81. Sur, 20 de noviembre de 1966, p.17. 


\section{A MODO DE REFLEXIÓN FINAL}

Decía Durkheim que cada sociedad segrega su cultura y, puesto que la generada en el contexto de la sociedad industrial avanzada "titubea» ${ }^{82}$, España ofertará un escenario estable, de satisfacción y regeneración, alternativo pero ineficaz en sus respuestas - por su vacuidad trasnochada- frente a la reflexión occidental. Que duda cabe que descanso y diversión serán los únicos fedatarios del marketing turístico, por mucho que en el franquismo se instaurara en nuevo entorno de diálogo cultural muy por encima de las posibilidades de un régimen tan obsoleto en su entorno político. En él, como botón de muestra, la imagen de la mujer y todo el cúmulo de prejuicios que la adornan recrean a un actor social impensable por su esquematismo en el marco de los países desarrollados, pero indispensable en la construcción de un universo, en fin, que como el hallado en nuestra costa, instaura un tiempo de la compensación psico-socioterapéutica, donde cada cual es dueño de divertirse a su modo. Unos modos, en definitiva, presa de los estereotipos y de un resumen simplista del pasado, del futuro y sobre todo de un presente animado por el consumo de símbolos que deprecia los hallazgos más pequeños y plurales de realidades y vivencias cotidianas.

82. Dumazedier, Joffre: «Realidades del ocio e ideologías», en Ocio y sociedad de clases, Barcelona, Fontanella, 1971, p. 43. 